has no deleterious effect on its purifying capacity. The accompanying graph shows the results of an experiment on a large scale at the Minworth Works of the Birmingham Tame and Rea District Drainage Board. During the period April 16-26, 1945, filters were treated with the following substances : creosote (400 gallons per acre), bleaching powder ( $6 \frac{1}{2}$ tons per acre), and D.D.T. in the form of emulsion (75 $\mathrm{lb}$. D.D.T. per acre) ; the numbers of emergent Psychoda and Anisopus flies caught in standard traps on the surface of the filters were then observed. Treatment with creosote gave the greatest reduction in numbers of Anisopus, but all the scouring organisms in the filter were killed and the biological film which later accumulated supported a secondary population of Psychoda. Bleaching powder caused the biological film to be discharged from the filter, and later there was a secondary peak in the emergence of Anisopus. With D.D.T. the numbers of both flies were greatly reduced and an active population of worms (Pachydrilus lineatus) and Collombola (Achorutes viaticus) remained and kept the growth of biological film in check.

Further experiments are being made, particularly to ascertain the minimum quantities of D.D.T. and the best method of application to control filter flies. At present D.D.T. is not available for civilian use; the possibility of applying it for control of flies at sewage works would, of course, depend on its price in comparison with the cost of alternative poisons.

Water Pollution Research Laboratory,

T. G. ToMnINSON.

Minworth, Birmingham. July 21.

\section{Use of Hydrochloric Acid for Softening Algal Tissues for Microtome Sections}

IN view of the increasing interest in marine algæ it seems apposite to record a method of treatment which has been found useful in preparing microtome sections of some Florideæ with particularly firm thalli. Formalin-alcohol, although a good fixative for cytological purposes, tends to harden such thalli, making them difficult to cut by microtome. Moreover, in those species which have an abundance of mucilaginous substances between the cells, the sections, when floated on water, swell considerably, twist, and escape from their casing of paraffin-wax. These difficulties can be avoided by treatment with warm hydrochloric acid in the case of Chondrus crispus, Gigartina mamillosa, Gracilaria confervoides and Rhodymenia palmata.

The method of treatment has been to put a covered dish containing a mixture of 90 c.c. of 70 per cent alcohol and 10 c.c. of hydrochloric acid in the embedding oven. When the liquid has reached the temperature of the oven, the piece of thallus to be treated is transferred to it from 70 per cent alcohol. The duration of the treatment required by different materials can only be found by experiment as it varies not only from species to species, but from the younger portions of the thallus to the older. For example, young pieces of Gigartina mamillosa, after fixation in formalin-alcohol, require 15 minutes, whereas similar pieces of Chondrus crispus require only 5 minutes. The duration of treatment should be kept to the minimum as continued immersion interferes with the staining of the nuclei and ultimately causes disintegration of the thallus. After treat- ment the thallus is washed thoroughly in 70 per cent alcohol and embedded in the usual way.

Of the algæ mentioned above, Gracilaria confervoides cuts reasonably well untreated, but sections of treated material are definitely superior. Gigartina mamillosa is very difficult to cut untreated after fixation in formalin-alcohol, but the youngest portions of the frond can be cut without treatment after fixation in Karpechenko's fluid. Even so, better results can be obtained by the use of hydrochloric acid. This is indispensable for the older parts of the frond, fixed in Karpechenko's fluid, but the time required is shorter than after formalin-alcohol. The improvement in all cases is more marked with sections cut at $5 \mu$ than at $10 \mu$.

\section{Kathleen M. Drew}

(MRS. BAKRR).

Department of Cryptogamic Botany,

University of Manchester.

Aug. 18.

\section{Activation Energy of lonic Migration in Molten Salts}

THE conductivity of ionic melts, such as alkali and alkaline earth halides, can be represented fairly well by an equation $x=A e^{-C / R T}$, where $C$ may be regarded as the energy necessary to effect the configurational change occurring in ionic migration. Deviations from this equation, $C$ varying with temperature, are found with some salts of a partially covalent character, for example, zinc chloride and lead chloride; with these salts, constitutional changes, such as dissociation, are likely to occur on rise of temperature.

The viscosity of ionic melts can be represented approximately by a similar equation: $\eta=A^{\prime} e^{B / R T}$, where $B$ is the energy necessary to produce the configurational change in viscous flow. Here also deviations have been recorded with some compounds of a partially covalent character ${ }^{1}$. Tabulated values for $B^{2}$ and $C^{3}$ are shown below.

\begin{tabular}{|c|c|c|c|c|}
\hline & $\begin{array}{c}\text { Equiv. conduct. } \\
\text { (temp. } 10 \text { per cent } \\
\text { above melting point } \\
\text { [abs.]) }\end{array}$ & $\begin{array}{c}C \\
\text { in cal. } / \mathrm{mole}\end{array}$ & $\stackrel{B}{B}$ in cal./mole & $r_{A} / r_{C}$ \\
\hline $\begin{array}{l}\mathrm{LiCl} \\
\mathrm{NaCl} \\
\mathrm{KCl} \\
\mathrm{RbCl} \\
\mathrm{CsCl} \\
\mathrm{NaBr} \\
\mathrm{KBr} \\
\mathrm{NaI} \\
\mathrm{KI} \\
\mathrm{CaCl}_{2} \\
\mathrm{BaCl}_{2}\end{array}$ & $\begin{array}{r}181 \\
149 \\
120 \\
95 \\
82 \\
145 \\
105 \\
150 \\
106 \\
65 \\
78\end{array}$ & $\begin{array}{l}1150 \\
1540 \\
2300 \\
2830 \\
3330 \\
1840 \\
2550 \\
1250 \\
2750 \\
4100 \\
4150\end{array}$ & $\begin{array}{r}8800 \\
9400 \\
7800 \\
= \\
10600 \\
7960 \\
7400 \\
9200 \\
9500 \\
-\end{array}$ & $\begin{array}{c}3 \cdot 01 \\
1.91 \\
1.36 \\
1 \cdot 22 \\
1.07 \\
2.05 \\
1 \cdot 47 \\
2.27 \\
1.62 \\
= \\
-\end{array}$ \\
\hline
\end{tabular}

The activation energy of viscous flow $(B)$ is always greater than that of ionic migration $(C)$. This must be due to a difference in mechanism between the two processes. Viscous flow is determined to a greater extent by the large anions than by the small cations. On the other hand, the electric conductance of the alkali halides is mainly due to the small cations, while the contribution of the large anions is very much smaller ${ }^{4}$. This is shown by the fact that the equivalent conductivity changes strongly with change of cation but very little with change of anion. These salts are predominantly cation-conductors in the solid state also ${ }^{5}$.

Thus, viscous flow involves a more far-reaching configurational change and higher energy barriers 